\title{
Corticotropin-Releasing Hormone Receptor 2 Signaling Promotes Mucosal Repair Responses after Colitis
}

\author{
Jill M. Hoffman, Stavroula Baritaki, Jonathan J. Ruiz, Aristea Sideri, and Charalabos Pothoulakis
}

From the Center for Inflammatory Bowel Diseases, Division of Digestive Diseases, David Geffen School of Medicine, University of California, Los Angeles, Los Angeles, California

Accepted for publication September 10, 2015.

Address correspondence to Charalabos Pothoulakis, M.D., MacDonald Research Laboratories 1240, 675 Charles E Young Dr. S, Los Angeles, CA 90095. E-mail: cpothoulakis@mednet.ucla.edu.

\begin{abstract}
The corticotropin-releasing hormone family mediates functional responses in many organs, including the intestine. Activation of corticotropin-releasing hormone receptor 2 (CRHR2) in the colonic mucosa promotes inflammation during acute colitis but inhibits inflammation during chronic colitis. We hypothesized that specific modulation of CRHR2 signaling in the colonic mucosa can promote restoration of the epithelium through stimulation of cell proliferative, migratory, and wound healing responses. Mucosal repair was assessed after dextran sodium sulfate (DSS)-induced colitis in mice receiving intracolonic injections of a CRHR2 antagonist or vehicle and in $\mathrm{Crhr}^{-/-}$mice. Histologic damage, cytokine expression, terminal deoxynucleotidyl transferase-mediated dUTP nick-end labeling, and Ki-67 immunoreactivity were evaluated. Cell viability, proliferation, and migration were compared between parental and CRHR2-overexpressing colonic epithelial cells. Protein lysates were processed for phosphoprotein assays and a wound healing assay performed in vitro. Administration of a CRHR2 antagonist after DSS-induced colitis increased disease activity, delayed healing, and decreased epithelial cell proliferation in vivo. Colons from these mice also showed increased apoptosis and proinflammatory cytokine expression. Compared with controls, $\mathrm{Crhr}^{-/-}$mice showed increased mortality in the DSS healing protocol. CRHR2-overexpressing cells had increased proliferation and migration compared with parental cells. Wound healing and signal transducer and activator of transcription 3 activity were elevated in CRHR2-overexpressing cells after urocortin 2 and IL- 6 treatment, suggesting advanced healing progression. Our results suggest that selective CRHR2 activation may provide a targeted approach to enhance mucosal repair pathways after colitis. (Am J Pathol 2016, 186: 134-144; http://dx.doi.org/10.1016/j.ajpath.2015.09.013)
\end{abstract}

Corticotropin-releasing hormone $(\mathrm{CRH})$, the primary mediator of the stress response, is expressed in both the central nervous system and periphery, including the intestine. The CRH family of peptides interacts with a variety of cell types in the intestinal mucosa, including epithelial cells, enteric neurons, and immune cells. ${ }^{1}$ In addition to $\mathrm{CRH}$, three distinct peptides known as urocortins (Ucn1, Ucn2, and $\mathrm{Ucn} 3$ ) bind to two types of $\mathrm{G}$ protein-coupled receptors to exert their effects, CRH receptor (CRHR) 1 and CRHR2. ${ }^{2-4}$ Ligand specificity for CRHR1 and CRHR2 differs among the CRH peptides, because CRH binds to CRHR1 with greater affinity than to CRHR2. In contrast, Ucn 1 has greater affinity for CRHR2 than CRHR1, and Ucn2 and Ucn3 bind exclusively to CRHR $2 .{ }^{3}$ Interactions between CRH receptors and their ligands modulate several functional and pathophysiologic responses within the gut, including stressinduced alterations in motility, ion secretion, and visceral pain, ${ }^{5}$ and the development and maintenance of intestinal

Supported by NIH Ruth L. Kirschstein National Research Service Award postdoctoral fellowship F32 DK102322-01 (J.M.H.) and grants PO1 DK 33506 (Project 1; C.P.), P30 DK 41301 (CURE:DDRC, Animal Core and Integrated Molecular Technologies Core; C.P.), P50 DK 64539 (Neuroendocrine Assay Core; C.P.), the Blinder Research Foundation for Crohn's Disease (J.M.H.), and the Eli and Edythe Broad Chair (C.P.).

Disclosures: None declared. 
inflammation. ${ }^{6-9}$ However, no studies to date implicate the CRH peptide family or their receptors in mucosal repair after colitis.

Mucosal repair of the intestinal barrier is a tightly coordinated response to injury that preserves homeostasis and limits the adverse effects of inflammation. After damage to the epithelium, intestinal epithelial cells migrate to the site of injury in a critical process known as epithelial restitution. ${ }^{10-12}$ Restitution is followed by epithelial cell proliferation and differentiation and is regulated by factors that promote cell viability and limit apoptosis. ${ }^{11,13}$ Inflammatory bowel disease (IBD) is a chronic relapsing inflammatory disorder that involves a defective epithelial barrier. ${ }^{14}$ Studies from our laboratory and others have found increased expression of CRHR2 and its ligands in mucosal biopsies from patients with IBD. ${ }^{15-17}$ Our previous animal studies also found a dual role for CRHR2 in the pathophysiology of intestinal inflammation, because CRHR2 signaling exerts proinflammatory effects during acute colitis ${ }^{18}$ yet confers protective actions during chronic inflammation. ${ }^{9}$ Furthermore, CRH-deficient mice are unable to initiate healing responses after acute experimental colitis, ${ }^{19}$ suggesting a role for the CRH peptide family in mucosal repair mechanisms.

On the basis of this evidence, we developed the hypothesis that CRHR2-dependent pathways contribute to intestinal mucosal repair and healing after acute intestinal inflammation. The overall aim of the present investigation was to determine whether specific modulation of CRHR2 signaling in the colonic mucosa can limit inflammation and promote restoration of the epithelial barrier through stimulation of mucosal repair responses after colitis. To accomplish this, we evaluated CRHR2 signaling in colonic epithelial cells in vitro and compared inflammatory and wound healing responses in wild-type and CRHR2 knockout $\left(\mathrm{Crhr}^{-1-}\right)$ mice in vivo. Studies in wildtype mice injected intracolonically with the selective CRHR2 antagonist, Astressin 2B (Ast2B), were also performed. Our results indicate that selective activation of CRHR2 in the intestinal epithelium after active inflammation can promote migratory, proliferative, and antiapoptotic signaling responses mediated by an IL-6/signal transducer and activator of transcription 3 (STAT3)-dependent pathway. Thus, CRHR2 may represent a novel therapeutic target to promote mucosal repair after colitis.

\section{Materials and Methods}

\section{Animals}

Male CD-1(ICR) mice 8 to 10 weeks of age were purchased from Charles River Laboratories (Wilmington, MA), and $C r h r 2^{-1-}$ mice were originally obtained as a gift from the laboratory of Dr. Wylie W. Vale (Salk Institute, La Jolla, CA) and backcrossed on a C57BL/6 background $\left(>\mathrm{N}_{10}\right)$. Wild-type and $\mathrm{Crhr}^{-l-}$ littermates were derived from subsequent heterozygous breeding in the Division of Laboratory Animal Medicine at the University of California, Los Angeles. Mice were housed two to four per cage, maintained on a 12:12 hour light-dark cycle, and given access to food and water ad libitum. After all in vivo experiments, mice were euthanized by carbon dioxide inhalation and cervical dislocation, and the distal colons were removed for further study. Animal protocols were approved by the Institutional Animal Care and Use Committee and the Office of Animal Research Oversight at University of California, Los Angeles.

\section{Model of Mucosal Repair after DSS Colitis}

To induce colitis, dextran sodium sulfate (DSS; $4 \%$ w/v; MP Biomedicals, Irvine, CA) was dissolved in tap water, and mice were given access ad libitum for 5 days. On days 5 to 14, mice were switched to water alone. On days 5 to 14 , mice were injected daily with vehicle or the CRHR2 antagonist Ast2B administered intraperitoneally ( $200 \mu \mathrm{L}$ of $30 \mu \mathrm{g} / \mathrm{kg}$ ) or intracolonically $(100 \mu \mathrm{L}$ of 30,15 , or $7.5 \mu \mathrm{g} / \mathrm{kg})$. Mice were weighed and monitored daily and euthanized on day 14 Severity of colitis was assessed by weight loss and determination of clinical ${ }^{20}$ and histological ${ }^{21}$ damage scores as previously described. Briefly, clinical scores were calculated on a scale of 0 to 3 for degree of weight loss, bleeding, stool consistency, and presence of rectal prolapse on day 14. Sections of colon fixed in $10 \%$ formalin, paraffin-embedded, and stained with hematoxylin and eosin were used for histological scoring. Scoring was performed by two independent investigators (J.M.H., J.J.R.) blinded to the treatment conditions, and their resulting scores were averaged. Scores were assigned on the basis of the degree of crypt damage (0 to 4), polymorphonuclear neutrophil infiltrate (0 to 3$)$, erosion (0 to 3 ), edema (0 to 3$)$, and epithelial regeneration (0 to 3$).^{21}$

\section{Immunohistochemistry and Imaging}

Formalin-fixed, paraffin-embedded colons were sectioned (5 $\mu \mathrm{m})$ and immunostained with a Ki-67 antigen (dilution 1:100; M7249; Dako, Carpinteria, CA) or terminal deoxynucleotidyl transferase dUTP nick-end labeling (TUNEL) with the ApopTag Plus Peroxidase in situ apoptosis detection kit (S7101; EMD Millipore, Temecula, CA) according to the manufacturer's instructions. To quantify Ki-67 immunoreactivity and TUNEL, pixel-based quantification of staining intensity was performed with an AxioImager.Z1 microscope equipped with AxioVision software version 4.6 (Zeiss, Jena, Germany). Stained sections were observed under a $20 \times$ objective lens. Digital images were collected with AxioCam, and the densitometric sum was calculated with the AutoMeasure module to avoid selection bias or interobserver effects.

\section{Experimental Compounds and Cell Culture Conditions}

Ast2B, CRH, IL-6, and tumor necrosis factor (TNF)- $\alpha$ were purchased from Bio-Techne (Minneapolis, MN). Ucn2 was purchased from Bachem (Bubendorf, Switzerland). Ast2B and Ucn2 were initially dissolved in dimethyl sulfoxide (Sigma-Aldrich, St. Louis, MO) and used at final 
concentrations of $\leq 0.75 \%$ dimethyl sulfoxide. For in vitro experiments, we used the human colonic mucosal epithelial cell line, NCM460 (INCELL Corporation, LLC, San Antonio, TX) derived from normal human colonic mucosa ${ }^{22}$ because these cells are less differentiated than cancer cell lines commonly used in the literature. Cells were incubated at $37^{\circ} \mathrm{C}$ with $5 \% \mathrm{CO}_{2}$ in $\mathrm{M} 3: \mathrm{D}$ culture media (INCELL Corporation) supplemented with $10 \%(\mathrm{v} / \mathrm{v})$ heat-inactivated fetal bovine serum, $10 \mathrm{U} / \mathrm{mL}$ penicillin, and $100 \mu \mathrm{g} / \mathrm{mL}$ streptomycin (Gibco, Carlsbad, CA).

\section{Lentiviral Transductions}

Construction of CRHR2-expressing lentivirus and stable cell transduction were performed as previously described. ${ }^{23}$ Briefly, NCM460 cells were infected with MCS-IRESStrawberry-hPGK-Puro lentiviral particles that contained a cytomegalovirus promoter driving expression of human Crhr2 (A0634; GeneCopoeia, Rockville, MD) or empty vector control $(\mathrm{EV})$. Selection of transduced clones was performed in culture media that contained $10 \mu \mathrm{g} / \mathrm{mL}$ puromycin (Sigma, Natick, MA). Only highly fluorescent cell clones were used in subsequent experiments, and CRHR2 induction was confirmed by real-time quantitative PCR.

\section{Transient Knockdown of CRHR2 and STAT3}

NCM460 cells were seeded in 6-well plates at a concentration of $3 \times 10^{5}$ cells/well in $1.8 \mathrm{~mL}$ complete medium. Transfection mix was prepared by diluting $50 \mathrm{nmol} / \mathrm{L}$ Silencer Select CRHR2 or STAT3 siRNAs and Lipofectamine RNAiMAX reagent (Life Technologies, Grand Island, NY) in $200 \mu \mathrm{L}$ OptiMEM, according to the manufacturer's instructions. The mix was added immediately into the cell suspension contained in each well. The transfection was repeated after 24 hours. Forty-eight hours after initial transfection, cells were harvested, and silencing was verified with real-time quantitative PCR.

\section{Real-Time Quantitative PCR}

The RNeasy Mini Kit (Qiagen, Valencia, CA) was used to extract RNA from colonic tissue or cultured cells, and complementary DNA was generated by a reverse-transcriptase reaction using reagents from Promega (Madison, WI). An Applied Biosystems 7500 Fast Real-time PCR System was used with Fast Universal PCR Master Mix and validated TaqMan Gene Expression Assays (Applied Biosystems, Foster City, CA) for TNF- $\alpha$ (Mm00443258_m1), IL-6 (Mm00446190_m1), IL-6 signal transducer (Mm00439665_m1), CXCL-1 (Mm04 207460_m1), CRHR2 (Mm00438303_m1, Hs00266401_m1), Ucn2 (Mm01227928_s1), and STAT3 (Hs01047580_m1). Resulting data were calculated with the 2- $\Delta \Delta \mathrm{Ct}$ method, and the level of mRNA expression was normalized to Rn18S (Mm04277571_s1, Hs99999901_s1). Expression of Rn18S was consistent across the conditions studied.

\section{Multiplex Cytokine Immunoassays}

Multiplex protein expression arrays were performed on protein lysates derived from our mouse experiments with the use of the ProcartaPlex Mouse Essential Th1/Th2 Cytokine Panel (eBioscience, Inc., San Diego, CA). Total protein was determined via the Pierce BCA Protein Assay kit (Life Technologies), and $20 \mu \mathrm{g}$ protein from each sample was loaded in duplicate and run on the BioPlex 3D Suspension Array System (Bio-Rad, Hercules, CA) according to the manufacturer's instructions.

\section{Western Blot Analysis}

Western blot analysis in protein lysates derived from our CRHR2-overexpressing and EV cell lines was performed with the Odyssey infrared imaging system (LI-COR Biosciences, Lincoln, NE). Briefly, $60 \mu \mathrm{g}$ total protein lysates were loaded in 10\% SDS-PAGE and transferred to Immobilon-FL polyvinylidene difluoride membranes (EMD Millipore, Temecula, CA). Membranes were blocked in Pierce Protein-Free phosphate-buffered saline blocking buffer (Life Technologies) for 1 hour at room temperature. Rabbit p-STAT3 (Tyr705), p-p44/p42 (extracellular signalregulated kinase 1/2), and glyceraldehyde-3-phosphate dehydrogenase primary antibodies (Cell Signaling Technology, Danvers, MA) were diluted 1:1000 in blocking buffer supplemented with $0.2 \%$ Tween 20 and incubated with membranes overnight at $4^{\circ} \mathrm{C}$. Anti-rabbit IRDye secondary antibody was diluted 1:15,000 and incubated with membranes for 1 hour at room temperature. After washes, fluorescent signals were analyzed with Image Studio Odyssey LI-COR software version 2.1 (LI-COR Biosciences).

\section{xCELLigence Real-Time Cell Analysis}

To assess NCM460 cell proliferation and migration we used a label-free real-time cell analysis platform (xCELLigence; Roche Applied Science, Indianapolis, IN) as previously described. ${ }^{24}$ For cell proliferation, $100 \mu \mathrm{L}$ complete culture medium was added to each well of an E-plate 96 at room temperature. The E-plate 96 was connected to the system, and background impedance was measured over 24 seconds. CRHR2-overexpressing and EV cells were resuspended in complete culture medium and adjusted to 10,000 cells $/ \mathrm{mL}$, which was determined as the optimal seeding concentration. Resuspended cells $(100 \mu \mathrm{L})$ were added to the E-plate 96 medium-containing wells. After 30 minutes of incubation at room temperature, the plate was placed into the cell culture incubator. Approximately 24 hours after seeding, when the cells were in the $\log$ growth phase (cell index $>0.5$ ), 100 $\mu \mathrm{L}$ medium was removed from each well and replaced with $100 \mu \mathrm{L}$ complete medium that contained Ucn 2 or CRH, Ast2B, or the combination. Controls received medium only. Cell proliferation was monitored every 15 minutes for 72 hours via the incorporated sensor electrode array of the 

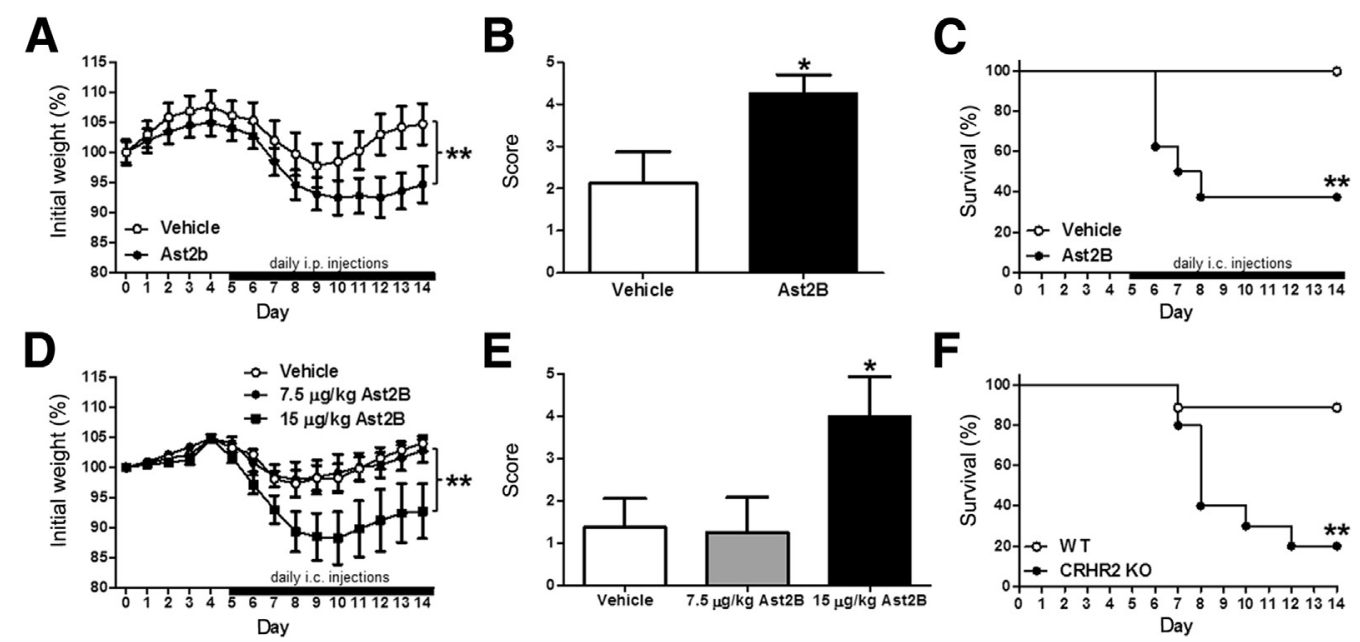

Figure 1 Inhibition of CRHR2 delays recovery from colitis in vivo. Mice received 4\% DSS for 5 days, followed by 10 days of water. Percentage of initial weight loss (A) and clinical scores (B) were calculated on day 14 from DSS-treated mice that received daily injections of $30 \mu \mathrm{g} / \mathrm{kg}$ Ast2B or vehicle i.p. daily from days 5 to 14. C: Kaplan-Meier survival curve for mice treated with $30 \mu \mathrm{g} / \mathrm{kg}$ Ast2B or vehicle daily from days 5 to 14. Percentage of initial weight loss (D) and clinical score (E) were calculated on day 14 from DSS-treated mice that received daily injections of 15 or $7.5 \mu \mathrm{g} / \mathrm{kg}$ Ast2B or vehicle i.c. daily from days 5 to 14 . F: Kaplan-Meier survival curve for DSS-treated Crhr2 K0 mice and WT littermates. Data are expressed as means \pm SEM. $n=8$ to 10 mice per group. ${ }^{*} P<0.05,{ }^{* \star} P<0.01$ versus vehicle-treated controls. Ast2B, astressin 2B; CRHR2, corticotropin-releasing hormone receptor 2; DSS, dextran sodium sulfate; i.c., intracolonic; K0, knockout; WT, wild-type.

E-Plate 96. Electrical impedance was measured with the xCELLigence system software version 1.2 .1 as a dimensionless parameter termed cell index, which is directly correlated to the proportion of the plate surface occupied by adherent cells. ${ }^{25}$ Proliferation rate is determined by calculating the slope of the line between two time points during the assay.

The rate of CRHR2-overexpressing and EV cell migration was also monitored in real time with the xCELLigence system (CIM-plate 16). Cells were serum-starved for 24 hours before the experiment. Complete culture medium (160 $\mu \mathrm{L}$ ) was added into the lower chamber of the CIM-plate 16 and serum-free medium $(50 \mu \mathrm{L})$ into the upper chamber. The plate was inserted into the platform and incubated for 1 hour. Meanwhile, dilutions of $1 \times 10^{6}$ cells $/ \mathrm{mL}$ were prepared in serum-free medium that contained Ucn2, Ast2B, or the combination. Cell suspensions $(100 \mu \mathrm{L})$ were added to each well of the upper chamber, and the impedance value of each well was monitored by the xCELLigence system for 50 hours, and data were expressed as a cell index value. Migration rate is determined by calculating the slope of the line between two time points during the assay.

\section{Determination of Cell Viability}

For viability assays, cells were plated in 96-well plates at 5000 cells/well. Cells were treated 24 hours later with 0.1 $\mu \mathrm{mol} / \mathrm{L}$ Ucn $2 \pm 50 \mathrm{ng} / \mathrm{mL}$ recombinant human TNF- $\alpha$. After 48 hours, cells were lyzed with CellTiter-Glo Luminescent Cell Viability Assay reagent (Promega), and luminescence was read on a plate reader (PerkinElmer, Waltham, MA). Percentage of cell viability was calculated relative to Ucn2treated EV cells.

\section{In Vitro Scratch Assay}

CRHR2-overexpressing and EV cells were serum-starved overnight, plated in 100-mm petri dishes, and grown to $90 \%$ confluence before scratch assay, as previously described. ${ }^{26}$ Briefly, the cell monolayer was scratched with a sterile $200-\mu \mathrm{L}$ pipette tip to simulate a wound, and the edge of the scratch was rinsed gently with serum-free medium. Cells were treated with $0.1 \mu \mathrm{mol} / \mathrm{L} \mathrm{Ucn} 2,15 \mathrm{ng} / \mathrm{mL}$ recombinant human IL-6, or the combination supplemented in serumfree medium. Images were captured at $\times 5$ magnification at 0 and 48 hours with the use of an AxioImager.Z1 microscope. Pixel-based quantification of total wound area (Densitometricarea $\left[\mathrm{Pixel}^{2}\right]$ ) was performed with the AutoMeasure module (AxioVision version 4.6; Zeiss).

\section{Statistical Analysis}

Statistical analyses were performed with GraphPad Prism version 5.0a (GraphPad Software, La Jolla, CA). Differences were determined by unpaired $t$-test, one-way analysis of variance, or a two-way analysis of variance with Bonferroni's posttest. Difference in survival was analyzed by KaplanMeier plot. $P<0.05$ was considered to be statistically significant. Data presented are means \pm SEM.

\section{Results}

Inhibition of CRHR2 Signaling in the Colonic Mucosa during the Repair Phase of DSS Colitis Inhibits Recovery from Intestinal Inflammation

We first assessed the involvement of CRHR2 signaling in mucosal repair after colitis in vivo, by administering the 

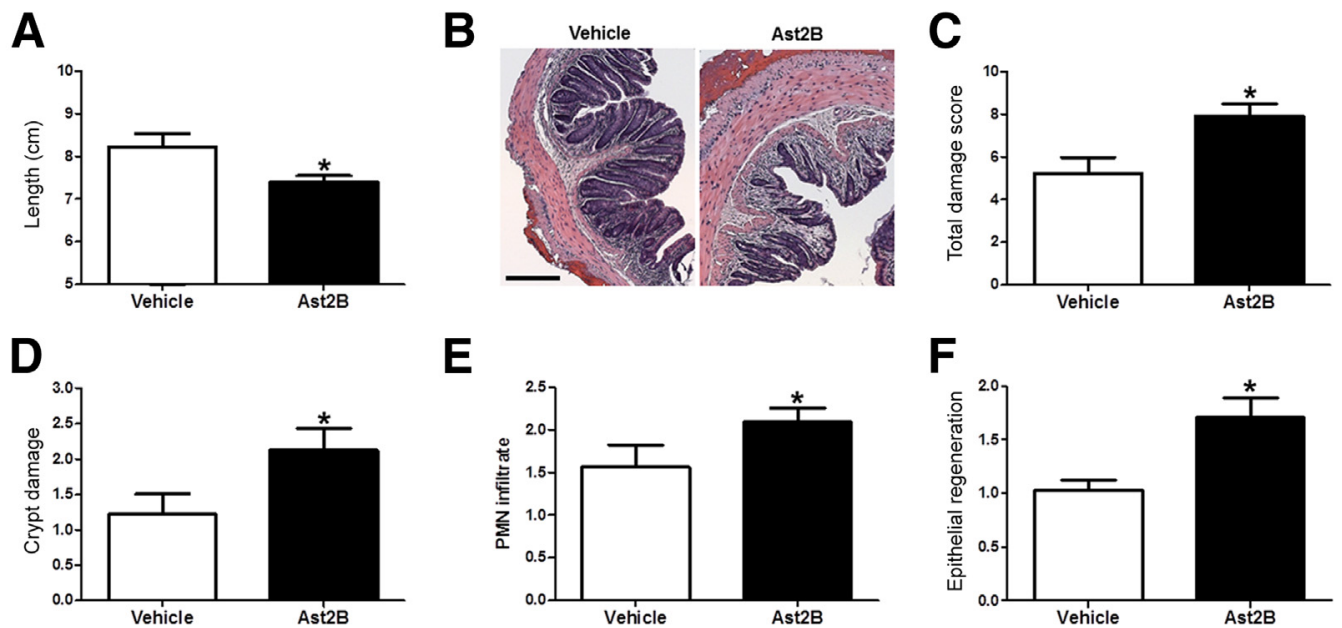

Figure 2 Targeted inhibition of CRHR2 signaling in the colonic mucosa after DSS colitis exacerbates histological damage scores. Colon length (A) and representative H\&E-stained sections (B) on day 14 from DSS-treated mice that received Ast2B or vehicle via daily i.c. injections after DSS colitis. Quantification of total histological damage score (C), crypt damage score (D), PMN infiltrate (E), and epithelial regeneration (F) at day 14. Data are expressed as means \pm SEM. $n=8$ mice per group. ${ }^{*} P<0.05$ versus vehicle-treated controls. Scale bar $=100 \mu \mathrm{m}$. Ast2B, astressin 2B; CRHR2, corticotropin-releasing hormone receptor 2; DSS, dextran sodium sulfate; H\&E, hematoxylin and eosin; i.c., intracolonic; PMN, polymorphonuclear.

CRHR2 antagonist Ast2B to mice after induction of DSS colitis. Mice received either an intraperitoneal (Figure 1A) or intracolonic (Figure 1D) injection of Ast2B or vehicle once daily for 10 days after withdrawal of DSS, and health status, weight loss, and disease activity were monitored. Mice receiving intraperitoneal injections of Ast2B lost more weight $(n=8$ per group; $P<0.01$ ) (Figure $1 \mathrm{~A}$ ) and had higher clinical scores $(2.125 \pm 0.7425$ versus $4.25 \pm 0.0284$; $n=8$ per group; $P<0.05$ ) (Figure $1 \mathrm{~B}$ ) than vehicle-treated controls. To more effectively target the colonic mucosa, we administered Ast2B intracolonically in a separate set of mice. Our initial results with a dose of $30 \mu \mathrm{g} / \mathrm{kg}$ are shown in the survival curve in Figure 1C $(n=8$ per group; $P<0.01)$. Subsequent groups of mice received injections of $15 \mu \mathrm{g} / \mathrm{kg}$ and $7.5 \mu \mathrm{g} / \mathrm{kg}$, and weight loss and clinical scores are shown in Figure 1, D and E ( $n=8$ per group). Because the $15-\mu \mathrm{g} / \mathrm{kg}$ dose yielded differences in disease activity $(P<0.05)$ and morbidity $(P<0.01)$ compared with vehicle-treated controls, this dose was used for all further experiments. $C r h r 2^{-1-}$ mice were used to assess the effect of genetic deletion of $\mathrm{Crhr} 2$ in the mucosal repair protocol (Figure 1F). By day 12 of the protocol, only 2 of the $10 \mathrm{Crhr} 2^{-/-}$mice survived (20\%), whereas only one ( $90 \%$ survival) of the wild-type littermates became moribund and was sacrificed $(n=10$ per group; $P<0.01$ ).

Analysis of colons from mice that received injections of 15 $\mu \mathrm{g} / \mathrm{kg}$ Ast2B revealed shorter colon length than vehicle-treated controls, indicating that CRHR2 inhibition leads to persistence of DSS colitis at day $14(8.225 \pm 0.3092 \mathrm{~cm}$ versus $7.4 \pm 0.1439 \mathrm{~cm} ; n=8$ per group; $P<0.05$ ) (Figure 2A). Histological analysis of hematoxylin and eosin-stained sections revealed that mice treated with $15 \mu \mathrm{g} / \mathrm{kg}$ Ast2B had more severe colitis and a higher overall damage score $(5.25 \pm 0.6597$ versus $7.906 \pm 0.6123 ; n=8$ per group; $P<0.05$ ) (Figure 2, B and $\mathrm{C}$ ) than vehicle-treated controls.
Individual components of the damage score, including crypt damage $(1.313 \pm 0.2444$ versus $2.188 \pm 0.2577$; $n=8$ per group; $P<0.05$ ) (Figure 2D), polymorphonuclear leukocyte infiltration $(1.5 \pm 0.2165$ versus $2.094 \pm 0.1632 ; n=8$ per group; $P<0.05$ ) (Figure $2 \mathrm{E}$ ), and epithelial regeneration $(1.031 \pm 0.09952$ versus $1.688 \pm 0.1687 ; n=8$ per group; $P<0.01$ ) (Figure $2 \mathrm{~F}$ ), were all increased in mice that received intracolonic injections of Ast2B compared with vehicle-treated controls.

\section{Inflammation-Induced Increases in Proinflammatory} Cytokine Production Persist after Inhibition of CRHR2 Signaling during the Mucosal Repair Phase of DSS Colitis

To assess the effects of CRHR2 inhibition on proinflammatory cytokine expression, real-time quantitative PCR was performed in full-thickness samples taken from the distal colons of mice that received intracolonic injections of Ast2B or vehicle after DSS colitis. We found that colonic TNF- $\alpha$, CXCL-1, and IL-6 mRNA levels were elevated in mice treated with intracolonic Ast2B $(n=8$ per group; $P<0.05)$ (Figure 3, A, C, and E). Protein expression levels of TNF- $\alpha$ and IL-6 ( $n=6$ per group; $P<0.05$ ) (Figure $3, \mathrm{~B}$ and D) also increased after administration of Ast2B, whereas the antiinflammatory cytokines IL-4, IL-5, and IL-12 remained unchanged (data not shown). Transcript levels for the IL-6 signal transducer (gp130) also increased in mice that received intracolonic Ast2B $(n=8$ per group; $P<0.05)$ (Figure $3 \mathrm{~F})$. To assess whether Ast2B treatment had any effect on CRHR2 signaling during the course of our treatment paradigm, we determined CRHR2 and Ucn2 mRNA expression. CRHR2 mRNA levels were unchanged (2.874 \pm 0.7547 versus $2.930 \pm 0.3204 ; n=8$ per group; $P=0.9467$ ), yet Ucn2 levels increased as a result of Ast2B treatment, suggesting that 

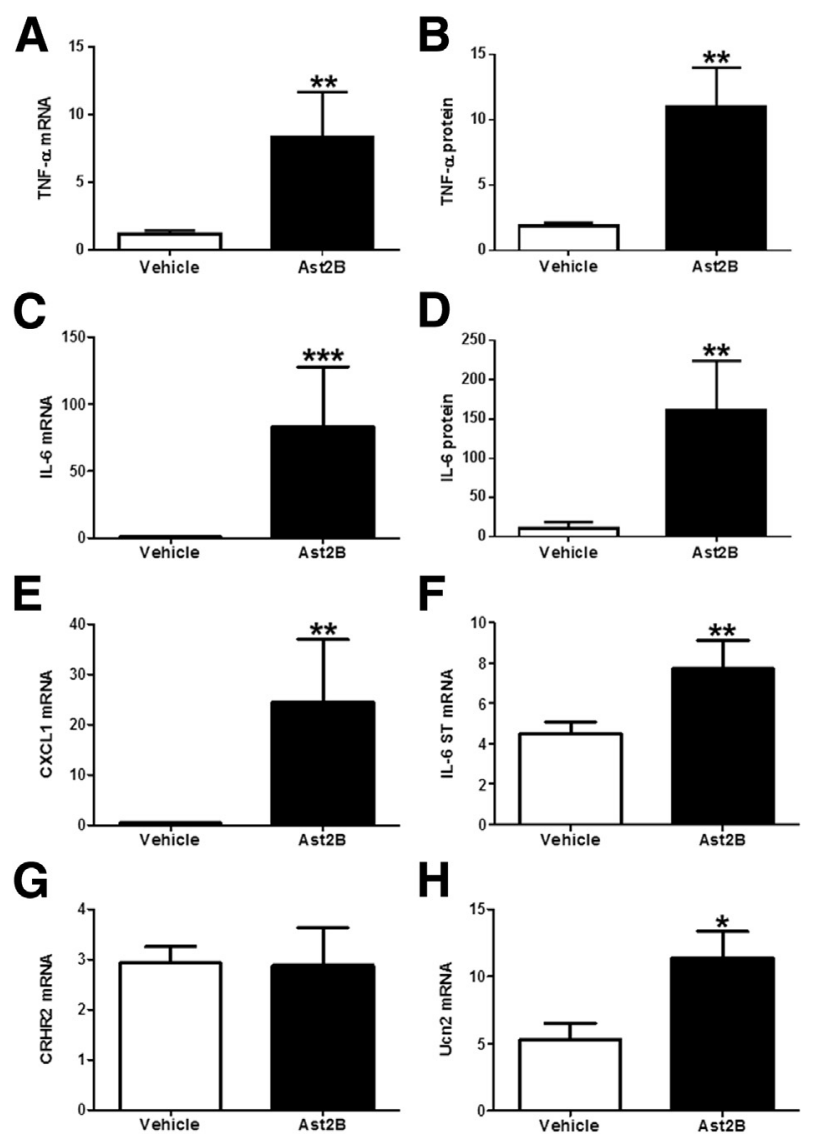

Figure 3 Proinflammatory cytokine mRNA expression increases after CRHR2 inhibition during recovery from DSS colitis. mRNA levels are elevated for TNF- $\alpha(\mathbf{A})$, IL-6 (C), CXCL1 (E), and the signal-transducing subunit of the IL-6 receptor $(\mathbf{F})$ in mice injected intracolonically with Ast2B compared with vehicle-treated controls. Protein expression levels (in $\mathrm{pg} / \mathrm{mL}$ ) of TNF- $\alpha$ (B) and IL-6 (D) are also increased. G: CRHR2 mRNA expression is unchanged as a result of Ast2B injections, whereas transcripts for Ucn2 $(\mathbf{H})$ are increased compared with controls. Data are expressed as means \pm SEM. $n=6$ to 8 mice per group. ${ }^{\star} P<0.05$, $* * P<0.01$, and $* * * P<0.001$ compared with vehicle-treated controls. Ast2B, astressin 2B; CRHR2, corticotropin-releasing hormone receptor 2; DSS, dextran sodium sulfate; ST, signal transducer; TNF, tumor necrosis factor; Ucn2, urocortin 2.

inhibition of the receptor leads to up-regulation of its ligand within the colonic mucosa $(5.302 \pm 1.201$ versus $11.40 \pm 1.957 ; n=8$ per group; $P<0.05$ ) (Figure 3, $\mathrm{G}$ and $\mathrm{H}$ ). These findings suggest that mucosal CRHR2 signaling promotes mucosal repair mechanisms and the resolution of intestinal inflammation.

\section{CRHR2 Stimulation Enhances Colonic Epithelial Cell Viability}

We next determined the effect of CRHR2 signaling on TNF- $\alpha$-induced cell death. EV cells treated with TNF- $\alpha$ displayed reduced cell viability compared with untreated cells $(100 \pm 4.608$ versus $78.88 \pm 2.814 ; n=3$ per group; $P<0.05$ ) (Figure 4A). This effect was inhibited in CRHR2overexpressing cells treated with TNF- $\alpha$ (78.88 \pm 2.814 versus $101.2 \pm 1.837 ; n=3$ per group; $P<0.05$ ), suggesting that increased levels of activated CRHR2 can promote intestinal epithelial cell viability.

To assess the effects on cell viability in our in vivo model, we also measured $\mathrm{TUNEL}^{+}$cells in colonic tissue sections from mice that had received intracolonic injections of Ast2B during the recovery phase of DSS colitis. TUNEL increased by $55 \%$ in Ast2B-treated mice compared with vehicle controls $\left(8.212 \mathrm{e}^{9} \pm 1.180 \mathrm{e}^{9}\right.$ versus $1.273 \mathrm{e}^{10} \pm 1.019 \mathrm{e}^{9} ; n=8 ; P<0.05$ ) (Figure 4, B and C), indicating increased levels of apoptosis, further supporting the concept that CRHR2 promotes mucosal healing and protects against programed cell death during recovery from active inflammation.

\section{CRHR2 Stimulation Promotes Colonic Epithelial Cell Proliferation in Vivo and in Vitro}

Colonic epithelial cell proliferation is an important feature of mucosal repair that starts within hours to days after injury to the epithelium. ${ }^{11}$ To assess the effect of CRHR2 signaling on epithelial cell proliferation, we created CRHR2overexpressing NCM460 cells. We then monitored cell proliferation in real time and found that Ucn2 or CRH treatment produced cell proliferatory responses that were more potent in CRHR2-overexpressing cells than in EV cells $(n=3)$ (Figure 5, A and B). These effects occurred in the absence of exogenously administrated Ucn2, suggesting that low endogenous ligand levels are sufficient for CRHR2 activation. Furthermore, cell proliferation was enhanced after exposure to Ucn2 in a dose-dependent manner. To confirm the specificity of the results on cell migration, cells were pretreated with Ast2B before stimulation with Ucn2, and the effects were attenuated ( $n=3$ ) (Figure 5, A and B).

To confirm our in vitro results in an in vivo setting we measured intestinal epithelial cell proliferation in sections from our mouse mucosal repair model by immunostaining for Ki-67, a nuclear marker of cell proliferation. Ki-67 staining was decreased by $74.9 \%$ in Ast2B-treated mice compared with vehicle controls $\left(7.154 \mathrm{e}^{9} \pm 2.080 \mathrm{e}^{9}\right.$ versus $2.061 \mathrm{e}^{9} \pm 3.654 \mathrm{e}^{8}$; $n=8$ per group; $P<0.05$ ) (Figure $5, \mathrm{C}$ and $\mathrm{D}$ ), further suggesting increased cell proliferation.

\section{CRHR2 Stimulation Promotes Colonic Epithelial Cell Migration in Vitro}

Cell migration represents an early response during wound healing in which epithelial cells migrate to the site of injury in an effort to restore barrier function after mucosal damage. ${ }^{27}$ To assess the effect of CRHR2 signaling on epithelial cell migration, we performed xCELLigence real-time cell analysis and found that Ucn2 treatment for 48 hours dosedependently increased single-cell migration, and these effects were more potent in CRHR2-overexpressing NCM460 cells than in EV cells $(n=3)$ (Figure 6A). As was seen for cell proliferation, these effects also occurred in the absence of 

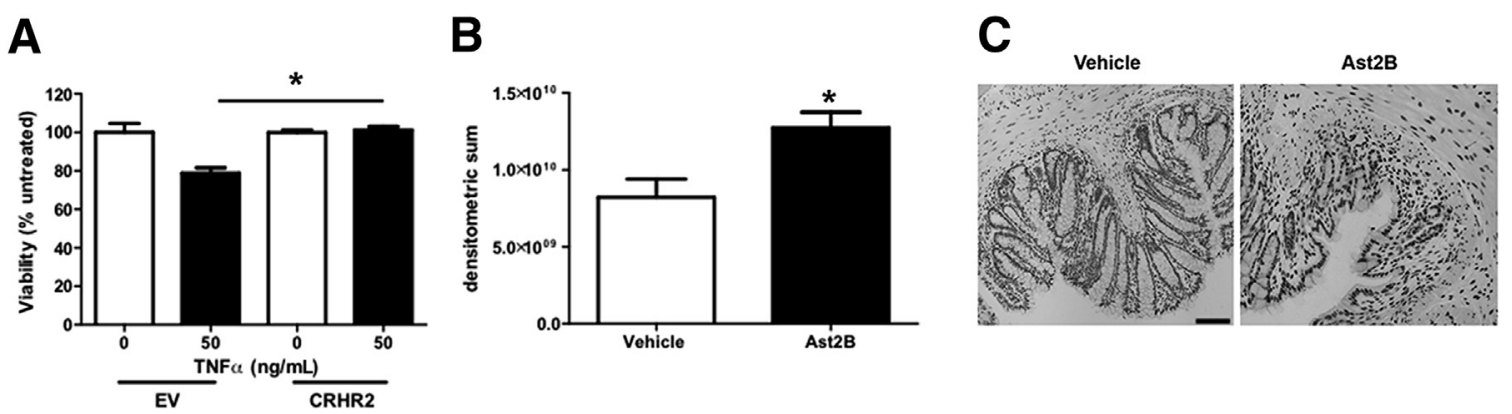

Figure 4 Stimulation of CRHR2 enhances colonic epithelial cell viability. A: CRHR2-overexpressing NCM460 cells are protected against TNF- $\alpha-i n d u c e d$ decreases in cell viability. B: Quantification of TUNEL. C: Representative images from TUNEL sections. Data are expressed as means \pm SEM. $n=3$ wells per group (A); $n=8$ mice per group (B). ${ }^{*} P<0.05$. Scale bar $=100 \mu \mathrm{m}$. Ast2B, astressin 2B; CRHR2, corticotropin-releasing hormone receptor 2; EV, empty vector; TNF, tumor necrosis factor; TUNEL, terminal deoxynucleotidyl transferase-mediated dUTP nick-end labeling.

exogenously administrated Ucn2, and migration was attenuated after pretreatment with Ast2B $(n=3)$ (Figure 6A).

To assess the effects of multi-cell interactions during epithelial cell migration, we plated CRHR2-overexpressing NCM460 cells and monitored wound healing with the use of the in vitro scratch assay model. After scratching of the epithelial cell monolayer, cell migration from the edge of the site of injury was imaged in real time. On the basis of the rationale that the addition of IL- 6 would mimic the proinflammatory environment that we observed in vivo, and IL-6/ STAT3 activation has been shown to promote migration and activation of downstream targets involved in wound healing in other cell types, including biliary ${ }^{28}$ and corneal ${ }^{29}$ epithelial cells, cells were treated with Ucn2, IL-6, or the combination. CRHR2-overexpressing NCM460 cells treated with IL-6 and Ucn 2 showed faster healing of wounded regions compared with control cells on day 2 by pixel-based quantification of total wound area $\left(43,419 \pm 8891\right.$ pixel $^{2}$ versus 288,010 $\pm 38,760$ pixel $^{2} ; n=3 ; P<0.05$ ) (Figure 6, B and C), suggesting that activation of CRHR2 can promote epithelial cell restitution in the presence of
IL-6. In addition, and on the basis of prior evidence for an Ucn2-STAT3 association, ${ }^{30}$ we hypothesized that CRHR2 signaling may stimulate STAT3 activation, resulting in increased epithelial cell migration to promote efficient mucosal healing. To address this hypothesis, we exposed CRHR2-overexpressing and EV cells to $15 \mathrm{ng} / \mathrm{mL}$ IL- $6+0.1$ $\mu \mathrm{mol} / \mathrm{L}$ Ucn 2 or vehicle for 30 minutes and measured pSTAT3 levels by Western blot analysis. CRHR2overexpressing cells had higher STAT3 activity in response to IL-6 and Ucn2 treatment than EV cells (Figure 6D). No change was observed in p44/42 (extracellular signal-regulated kinase 1/2) at 30 minutes (data not shown). These findings suggest that CRHR2 signaling may regulate IL-6-mediated STAT3 activation in intestinal epithelial cells.

To further confirm the specificity of the in vitro findings, we silenced expression of CRHR2 or STAT3 in CRHR2-overexpressing NCM460 cells with the use of siRNA transfection and stimulated them with $15 \mathrm{ng} / \mathrm{mL}$ IL- $6+0.1 \mu \mathrm{mol} / \mathrm{L}$ Ucn2. Colonic epithelial cell migration and proliferation were inhibited after CRHR2 knockdown (Figure 7, A and C), consistent with our findings after
A

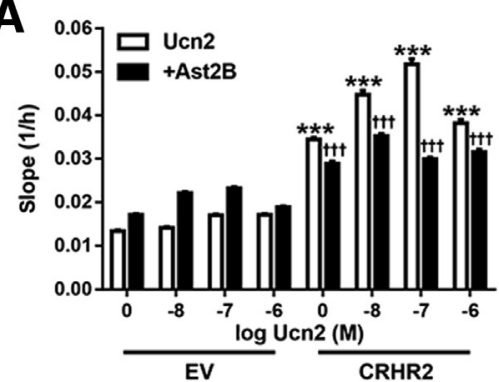

C

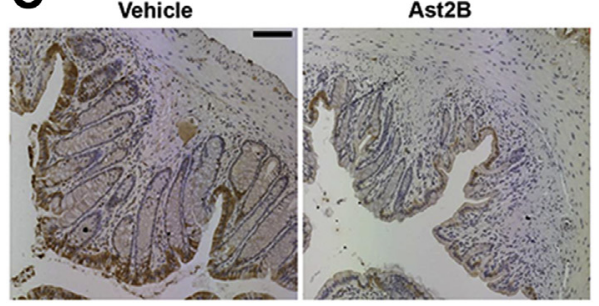

B

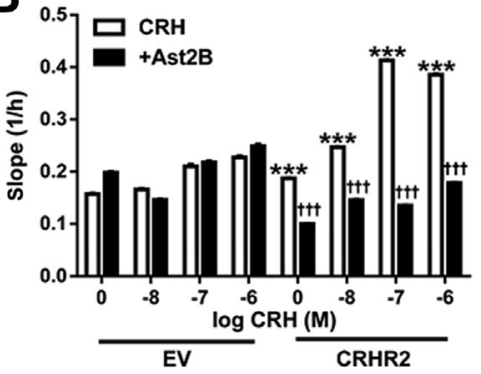

D

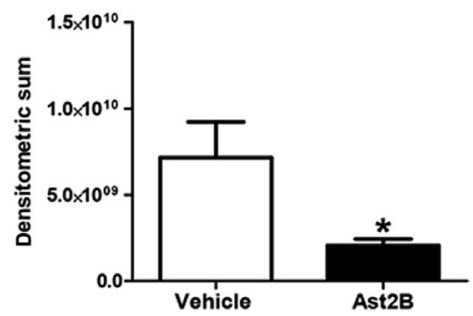

Figure 5 Stimulation of CRHR2 promotes colonic epithelial cell proliferation. A and B: Human CRHR2-transfected NCM460 cells (CRHR2) and EV transfected cells were stimulated with varying concentrations of Ucn2 (A) or CRH (B) with or without pretreatment of $1 \mu \mathrm{mol} / \mathrm{L} A s t 2 B$, and proliferation was assessed with the use of the slope $(1 / \mathrm{h})$ of data collected with the xCELLigence software. C: Representative images from Ki-67 immunoreactive sections. D: Quantification of Ki-67 immunohistochemistry with the use of pixel-based densitometry. Data are expressed as means \pm SEM. $n=3$ wells per group (A); $n=8$ mice per group (D). ${ }^{*} P<0.05$ compared with vehicletreated controls; ${ }^{* * *} P<0.001$ versus EV controls; ${ }^{\dagger \dagger} P<0.001$ versus Ucn2 or CRH treatment of CRHR2 cells alone. Scale bar $=100 \mu \mathrm{m}$. Ast2B, astressin 2B; CHR, corticotropin-releasing hormone; CRHR2, corticotropin-releasing hormone receptor 2; EV, empty vector; Ucn2, urocortin 2. 
A

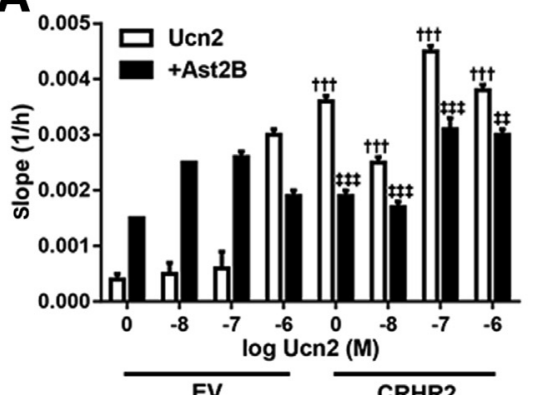

B

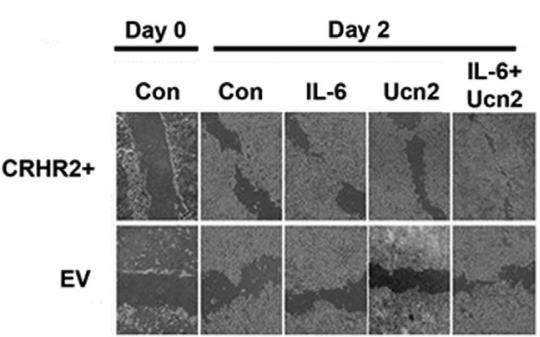

C

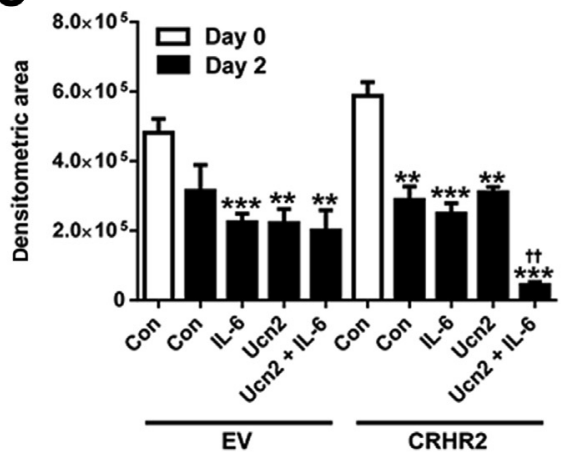

D

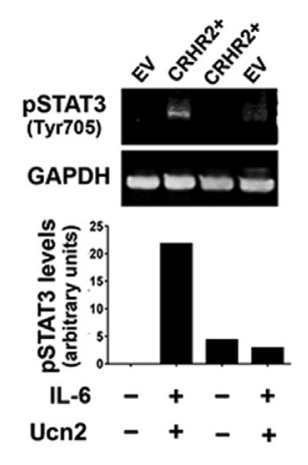

Figure 6 Stimulation by CRHR2 promotes colonic epithelial cell migration. A: Human CRHR2transfected human colonic mucosal epithelial NCM460 cells (CRHR2) and EV transfected cells were stimulated with varying concentrations of Ucn2 with or without pretreatment of $1 \mu \mathrm{mol} / \mathrm{L}$ Ast2B, and migration was assessed with the slope $(1 / h)$ of data collected with XCELLigence software. B: Representative micrographs from CRHR2overexpressing $\left(\mathrm{CRHR}^{+}\right)$or EV cells treated with IL-6, Ucn2, or the combination after scratch assay at 0 and 48 hours. C: Pixel-based quantification of total wound area after scratch assay. D: Ucn2 and IL-6-induced STAT3 phosphorylation (Tyr705) in EV and CRHR2-overexpressing NCM460 cells, as assessed by Western blot analysis. Data are expressed as means \pm SEM. $n=3$ wells per group. ${ }^{* *} P<0.01,{ }^{* * *} P<0.001$ versus control-treated cells on day $0 ;{ }^{\dagger \dagger} P<0.01$ versus Ucn2 treatment alone; ${ }^{\dagger \dagger} P<0.001$ versus Ucn2-treated EV cells; $\sharp \ddagger P<0.01$ versus Ucn2-treated CRHR2 cells; $\ddagger \ddagger \ddagger P<0.001$ versus Ucn2-treated CRHR2 cells. Ast2B, astressin 2B; CON, control; CRHR2, corticotropin-releasing hormone receptor 2; $\mathrm{EV}$, empty vector; GAPDH, glyceraldehyde-3-phosphate dehydrogenase; $M$, molar concentration; pSTAT3, phosphorylated STAT3; STAT3, signal transducer and activator of transcription 3; Ucn2, urocortin 2. pharmacologic inhibition of CRHR2 signaling with Ast2B. Similarly, STAT3 silencing attenuated the migratory response, further supporting the involvement of the STAT3 survival pathway in our CRHR2-mediated effects on mucosal repair (Figure 7, B and D).

\section{Discussion}

Mucosal healing is a desired therapeutic endpoint in the treatment of IBD, ${ }^{12}$ and interventions that promote restoration of the epithelial barrier are needed to limit inflammation and to prevent future injury. Here, we show that selective inhibition of CRHR2 signaling in the intestinal mucosa of mice after experimental colitis leads to increased disease activity, delayed healing, and decreased epithelial cell proliferation. Colons from these mice also showed increased TUNEL and elevated TNF- $\alpha$ mRNA and protein levels. Treatment of CRHR2-overexpressing NCM460 cells with CRH or Ucn2 increased epithelial cell proliferation and migration, and wound healing was accelerated in CRHR2overexpressing NCM460 cells after Ucn2 and IL-6 treatment, suggesting advanced healing progression. Finally, stimulation of CRHR2-overexpressing colonic epithelial cells with Ucn2 and the proinflammatory cytokine IL-6 increased STAT3 activity. Taken together, these results indicate that CRHR2 signaling promotes mucosal repair in vivo and in human colonocytes in vitro.

In the present investigation, we studied mucosal repair responses after DSS colitis. This model was used by others, ${ }^{31-33}$ and has been described as "an ideal model to study normal mucosal healing." 34 Previous studies that involved our laboratory and others have shown that mice deficient in CRH or CRHR2 show increased severity of DSS-induced colitis beyond the 6 day time point, suggesting a protective role for CRHR2/ligand signaling during chronic colitis and mucosal repair. ${ }^{9,19}$ Thus, the design of our in vivo studies included both intraperitoneal and intracolonic administration of the selective CRHR2 antagonist Ast2B.
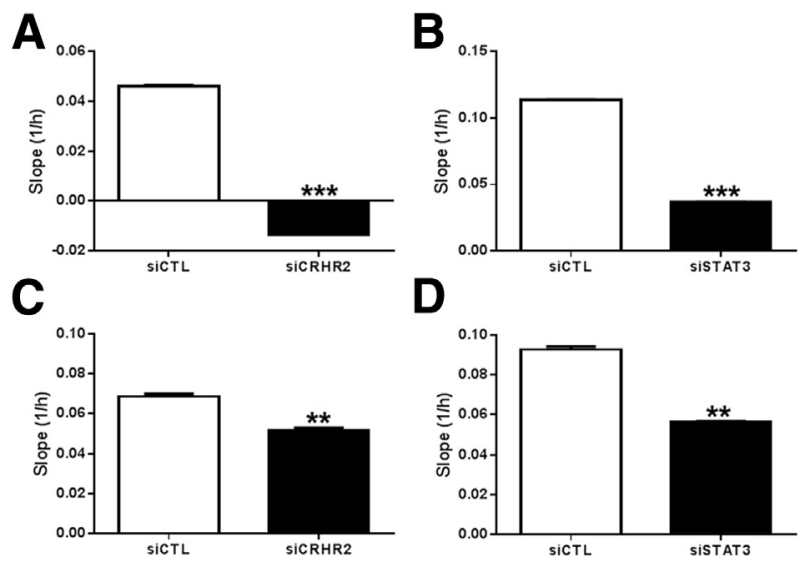

Figure 7 Down-regulation of CRHR2 or STAT3 by siRNA inhibits colonic epithelial cell migration and proliferation. Cell migration was assayed by the slope $(1 / h)$ of data collected with xCELLigence in CRHR2-overexpressing NCM460 cells transfected with siRNA against CRHR2 (A), STAT3 (B), or siCTL after stimulation with $0.1 \mu \mathrm{mol} / \mathrm{L}$ Ucn2 and IL-6. C and D: Cell proliferation was measured with the slope $(1 / \mathrm{h})$ of data collected with xCELLigence in CRHR2 (C), STAT3 (D), or siCTL siRNA transfected CRHR2-overexpressing NCM460 cells after stimulation with $0.1 \mu \mathrm{mol} / \mathrm{L}$ Ucn2 and IL-6. Data are expressed as means \pm SEM. $n=2$ wells per group. ${ }^{* *} P<0.01$, ${ }^{* * * P}<0.001$. CRHR2, corticotropin-releasing hormone receptor 2; siCTL, control siRNA; STAT3, signal transducer and activator of transcription 3; Ucn2, urocortin 2. 
Peptide antagonists such as Ast2B, when administered in the periphery, do not cross the blood-brain barrier $^{35}$ and offer a potential advantage over $\mathrm{Crhr} 2^{-1-}$ mice because centrally mediated effects or compensatory mechanisms that may occur during development are not potential confounders to the observed effects. Furthermore, Ast2B is both potent and highly selective for CRHR2 (concentration that inhibits $50 \%=1.3 \mathrm{nmol} / \mathrm{L}$ for CRHR2 versus concentration that inhibits $50 \%>500 \mathrm{nmol} / \mathrm{L}$ for CRHR 1$)^{35}$ and exhibits a long duration of action in in vivo studies. ${ }^{36}$

Depending on the cell type and the local environment, activation of CRHR2 can enhance or inhibit cellular responses involved in mucosal repair, including cell migration ${ }^{9,37,38}$ and proliferation. ${ }^{9,39,40}$ To further assess the role of CRHR2 signaling in these responses, we established an in vitro system with the use of the human colon-derived cell line NCM460 stably transfected with human CRHR2. After transfection, we showed that CRHR2 stimulation with CRH or Ucn2 promotes epithelial cell migration and proliferation. Several lines of evidence indicate a protective role for CRHR2 in cell survival, ${ }^{40-42}$ particularly in studies that involved the myocardium, where CRHR2 is highly expressed ${ }^{43}$ and activation of CRHR2 protects cardiac muscle cells from hypoxia/ ischemia-induced apoptosis. ${ }^{44-46}$ Furthermore, human studies have shown improvements in cardiac function after systemic Ucn2 administration in healthy patients ${ }^{47}$ and patients with heart failure, ${ }^{48,49}$ supporting the potential use of CRHR2 ligands clinically.

Cytokines play a central role in the regulation of both intestinal inflammation and mucosal repair mechanisms. ${ }^{50}$ Treatments that neutralize the proinflammatory actions of TNF- $\alpha$ promote mucosal healing and are a standard of current IBD treatment paradigms. ${ }^{50,51}$ In addition, production of the key proinflammatory cytokine IL- 6 correlates with the degree of active intestinal inflammation in IBD patients, ${ }^{52}$ further supporting the concept that therapeutic interventions that modulate cytokine production and/or release may promote mucosal repair after inflammation. $\mathrm{CRH}$ receptor activation can also regulate release of cytokines from a variety of cell types. ${ }^{53-56}$ Consistent with these observations, we show CRHR2-mediated increases in TNF- $\alpha$, IL-6, and CXCL1 expression associated with delayed intestinal mucosal repair in vivo. Furthermore, CRHR2-overexpressing NCM460 cells treated with Ucn2 and IL-6 display improved migratory and healing responses. Binding of IL- 6 to its receptor leads to activation of Janus kinase 2 and subsequent phosphorylation of STAT3, which has known roles in mucosal repair $^{57-59}$ and IBD pathophysiology. ${ }^{60,61}$ STAT3 is also important in the maintenance of local immune responses and intestinal homeostasis, ${ }^{58,61-63}$ whereas activation of STAT3 downstream of $\mu$-opioid receptor signaling in intestinal epithelial cells is associated with mucosal repair after colitis. ${ }^{59}$ Although further studies are required to delineate the precise mechanisms by which CRHR2 signals via IL-6/STAT3 in the intestinal epithelium, we show evidence for an important role for activation of the STAT3 survival pathway downstream of
CRHR2. Although we cannot exclude the involvement of other survival pathways, our data suggest that IL-6/STAT3 signaling may contribute to intestinal homeostasis and epithelial barrier regulation after inflammation.

In conclusion, these findings provide, to our knowledge, the first demonstration that the CRH family of peptides can modulate mucosal repair mechanisms in the intestine and that selective targeting of CRHR2 intracolonically promotes epithelial cell proliferation, migration, and viability after experimental colitis in vivo and in human colonocytes in vitro. We suggest that CRHR2 activation can initiate restoration of the epithelial barrier during the recovery phase of intestinal inflammation by a signaling mechanism that involves phosphorylation of STAT3. These results support exploration of targeted therapeutic approaches to enhance healing of the intestinal lining and to promote remission from disease during intestinal inflammation and in patients with IBD.

\section{Acknowledgments}

We thank the UCLA Translational Pathology Core Laboratory, the Immunohistochemistry Core in the Department of Pathology and Laboratory Medicine, and the Center for Systems Biomedicine (Integrated Molecular Technologies Core) for their technical assistance with the xCELLigence studies. $\mathrm{Crhr} 2^{-1-}$ mice were a gift from the laboratory of Dr. Wylie W. Vale (Salk Institute, La Jolla, CA).

\section{References}

1. Gross KJ, Pothoulakis C: Role of neuropeptides in inflammatory bowel disease. Inflamm Bowel Dis 2007, 13:918-932

2. Chalmers DT, Lovenberg TW, Grigoriadis DE, Behan DP, De Souza EB: Corticotrophin-releasing factor receptors: from molecular biology to drug design. Trends Pharmacol Sci 1996, 17: $166-172$

3. Hillhouse EW, Grammatopoulos DK: The molecular mechanisms underlying the regulation of the biological activity of corticotropinreleasing hormone receptors: implications for physiology and pathophysiology. Endocr Rev 2006, 27:260-286

4. Bale TL, Vale WW: CRF and CRF receptors: role in stress responsivity and other behaviors. Annu Rev Pharmacol Toxicol 2004, 44: $525-557$

5. Tache Y, Million M: Role of corticotropin-releasing factor signaling in stress-related alterations of colonic motility and hyperalgesia. J Neurogastroenterol Motil 2015, 21:8-24

6. Gay J, Kokkotou E, O'Brien M, Pothoulakis C, Karalis KP: Corticotropin-releasing hormone deficiency is associated with reduced local inflammation in a mouse model of experimental colitis. Endocrinology 2008, 149:3403-3409

7. Wlk M, Wang CC, Venihaki M, Liu J, Zhao D, Anton PM, Mykoniatis A, Pan A, Zacks J, Karalis K, Pothoulakis C: Corticotropin-releasing hormone antagonists possess anti-inflammatory effects in the mouse ileum. Gastroenterology 2002, 123:505-515

8. Anton PM, Gay J, Mykoniatis A, Pan A, O'Brien M, Brown D, Karalis K, Pothoulakis C: Corticotropin-releasing hormone $(\mathrm{CRH})$ requirement in Clostridium difficile toxin A-mediated intestinal inflammation. Proc Natl Acad Sci U S A 2004, 101:8503-8508 
9. Im E, Rhee SH, Park YS, Fiocchi C, Tache Y, Pothoulakis C: Corticotropin-releasing hormone family of peptides regulates intestinal angiogenesis. Gastroenterology 2010, 138:2457-2467, 2467.e1-e5

10. Taupin D, Podolsky DK: Trefoil factors: initiators of mucosal healing. Nat Rev Mol Cell Biol 2003, 4:721-732

11. Sturm A, Dignass AU: Epithelial restitution and wound healing in inflammatory bowel disease. World J Gastroenterol 2008, 14: 348-353

12. Neurath MF: New targets for mucosal healing and therapy in inflammatory bowel diseases. Mucosal Immunol 2014, 7:6-19

13. Neurath MF, Travis SP: Mucosal healing in inflammatory bowel diseases: a systematic review. Gut 2012, 61:1619-1635

14. Laukoetter MG, Nava P, Nusrat A: Role of the intestinal barrier in inflammatory bowel disease. World J Gastroenterol 2008, 14: $401-407$

15. Moss AC, Anton P, Savidge T, Newman P, Cheifetz AS, Gay J, Paraschos S, Winter MW, Moyer MP, Karalis K, Kokkotou E, Pothoulakis C: Urocortin II mediates pro-inflammatory effects in human colonocytes via corticotropin-releasing hormone receptor 2alpha. Gut 2007, 56:1210-1217

16. Kawahito Y, Sano H, Mukai S, Asai K, Kimura S, Yamamura Y, Kato H, Chrousos GP, Wilder RL, Kondo M: Corticotropin releasing hormone in colonic mucosa in patients with ulcerative colitis. Gut 1995, 37:544-551

17. Saruta M, Takahashi K, Suzuki T, Torii A, Kawakami M, Sasano H: Urocortin 1 in colonic mucosa in patients with ulcerative colitis. J Clin Endocrinol Metab 2004, 89:5352-5361

18. Kokkotou E, Torres D, Moss AC, O'Brien M, Grigoriadis DE, Karalis K, Pothoulakis C: Corticotropin-releasing hormone receptor 2-deficient mice have reduced intestinal inflammatory responses. J Immunol 2006, 177:3355-3361

19. Chaniotou Z, Giannogonas P, Theoharis S, Teli T, Gay J, Savidge T, Koutmani Y, Brugni J, Kokkotou E, Pothoulakis C, Karalis KP: Corticotropin-releasing factor regulates TLR4 expression in the colon and protects mice from colitis. Gastroenterology 2010, 139: 2083-2092

20. Cooper HS, Murthy SN, Shah RS, Sedergran DJ: Clinicopathologic study of dextran sulfate sodium experimental murine colitis. Lab Invest 1993, 69:238-249

21. Ungaro R, Fukata M, Hsu D, Hernandez Y, Breglio K, Chen A, Xu R, Sotolongo J, Espana C, Zaias J, Elson G, Mayer L, KoscoVilbois M, Abreu MT: A novel Toll-like receptor 4 antagonist antibody ameliorates inflammation but impairs mucosal healing in murine colitis. Am J Physiol Gastrointest Liver Physiol 2009, 296: G1167-G1179

22. Moyer MP, Manzano LA, Merriman RL, Stauffer JS, Tanzer LR: NCM460, a normal human colon mucosal epithelial cell line. In Vitro Cell Dev Biol Anim 1996, 32:315-317

23. Corvinus FM, Orth C, Moriggl R, Tsareva SA, Wagner S, Pfitzner EB, Baus D, Kaufmann R, Huber LA, Zatloukal K, Beug H, Ohlschlager P, Schutz A, Halbhuber KJ, Friedrich K: Persistent STAT3 activation in colon cancer is associated with enhanced cell proliferation and tumor growth. Neoplasia 2005, 7:545-555

24. Limame R, Wouters A, Pauwels B, Fransen E, Peeters M, Lardon F, De Wever O, Pauwels P: Comparative analysis of dynamic cell viability, migration and invasion assessments by novel real-time technology and classic endpoint assays. PLoS One 2012, 7:e46536

25. Atienza JM, Yu N, Kirstein SL, Xi B, Wang X, Xu X, Abassi YA: Dynamic and label-free cell-based assays using the real-time cell electronic sensing system. Assay Drug Dev Technol 2006, 4: 597-607

26. Denker SP, Barber DL: Cell migration requires both ion translocation and cytoskeletal anchoring by the Na-H exchanger NHE1. J Cell Biol 2002, 159:1087-1096

27. Dignass AU, Podolsky DK: Cytokine modulation of intestinal epithelial cell restitution: central role of transforming growth factor beta. Gastroenterology 1993, 105:1323-1332
28. Jiang GX, Zhong XY, Cui YF, Liu W, Tai S, Wang ZD, Shi YG, Zhao SY, Li CL: IL-6/STAT3/TFF3 signaling regulates human biliary epithelial cell migration and wound healing in vitro. Mol Biol Rep 2010, 37:3813-3818

29. Ebihara N, Matsuda A, Nakamura S, Matsuda H, Murakami A: Role of the IL-6 classic- and trans-signaling pathways in corneal sterile inflammation and wound healing. Invest Ophthalmol Vis Sci 2011, 52:8549-8557

30. Sashinami H, Kageyama K, Suda T, Nakane A: Urocortin 2 suppresses host resistance to Listeria monocytogenes infection via upregulation of interleukin-10. Endocrinology 2005, 146:5003-5011

31. Elson CO, Cong Y, Brandwein S, Weaver CT, McCabe RP, Mahler M, Sundberg JP, Leiter EH: Experimental models to study molecular mechanisms underlying intestinal inflammation. Ann N Y Acad Sci 1998, 859:85-95

32. Williams KL, Fuller CR, Dieleman LA, DaCosta CM, Haldeman KM, Sartor RB, Lund PK: Enhanced survival and mucosal repair after dextran sodium sulfate-induced colitis in transgenic mice that overexpress growth hormone. Gastroenterology 2001, 120: 925-937

33. Dieleman LA, Elson CO, Tennyson GS, Beagley KW: Kinetics of cytokine expression during healing of acute colitis in mice. Am J Physiol 1996, 271(1 Pt 1):G130-G136

34. Lund PK, Zuniga CC: Intestinal fibrosis in human and experimental inflammatory bowel disease. Curr Opin Gastroenterol 2001, 17: $318-323$

35. Rivier J, Gulyas J, Kirby D, Low W, Perrin MH, Kunitake K, DiGruccio M, Vaughan J, Reubi JC, Waser B, Koerber SC, Martinez V, Wang L, Tache Y, Vale W: Potent and long-acting corticotropin releasing factor (CRF) receptor 2 selective peptide competitive antagonists. J Med Chem 2002, 45:4737-4747

36. Rivier JE, Rivier CL: Corticotropin-releasing factor peptide antagonists: design, characterization and potential clinical relevance. Front Neuroendocrinol 2014, 35:161-170

37. Jin L, Li C, Li R, Sun Z, Fang X, Li S: Corticotropin-releasing hormone receptors mediate apoptosis via cytosolic calciumdependent phospholipase $\mathrm{A}(2)$ and migration in prostate cancer cell RM-1. J Mol Endocrinol 2014, 52:255-267

38. Ducarouge B, Pelissier-Rota M, Laine M, Cristina N, Vachez Y, Scoazec JY, Bonaz B, Jacquier-Sarlin M: CRF2 signaling is a novel regulator of cellular adhesion and migration in colorectal cancer cells. PLoS One 2013, 8:e79335

39. Hao Z, Huang Y, Cleman J, Jovin IS, Vale WW, Bale TL, Giordano FJ: Urocortin2 inhibits tumor growth via effects on vascularization and cell proliferation. Proc Natl Acad Sci U S A 2008, 105:3939-3944

40. Chatzaki E, Lambropoulou M, Constantinidis TC, Papadopoulos N, Tache Y, Minopoulos G, Grigoriadis DE: Corticotropin-releasing factor (CRF) receptor type 2 in the human stomach: protective biological role by inhibition of apoptosis. J Cell Physiol 2006, 209:905-911

41. Jin L, Zhang Q, Guo R, Wang L, Wang J, Wan R, Zhang R, Xu Y, Li S: Different effects of corticotropin-releasing factor and urocortin 2 on apoptosis of prostate cancer cells in vitro. J Mol Endocrinol 2011, 47: 219-227

42. Chandras C, Koutmani Y, Kokkotou E, Pothoulakis C, Karalis KP: Activation of phosphatidylinositol 3-kinase/protein kinase B by corticotropin-releasing factor in human monocytes. Endocrinology 2009, 150:4606-4614

43. Perrin M, Donaldson $\mathrm{C}$, Chen $\mathrm{R}$, Blount A, Berggren $\mathrm{T}$, Bilezikjian L, Sawchenko P, Vale W: Identification of a second corticotropin-releasing factor receptor gene and characterization of a cDNA expressed in heart. Proc Natl Acad Sci U S A 1995, 92: 2969-2973

44. Nishikimi T, Miyata A, Horio T, Yoshihara F, Nagaya N, Takishita S, Yutani C, Matsuo H, Matsuoka H, Kangawa K: Urocortin, a member of the corticotropin-releasing factor family, in normal and diseased heart. Am J Physiol Heart Circ Physiol 2000, 279:H3031-H3039 
45. Chanalaris A, Lawrence KM, Stephanou A, Knight RD, Hsu SY, Hsueh AJ, Latchman DS: Protective effects of the urocortin homologues stresscopin (SCP) and stresscopin-related peptide (SRP) against hypoxia/reoxygenation injury in rat neonatal cardiomyocytes. J Mol Cell Cardiol 2003, 35:1295-1305

46. Brar BK, Jonassen AK, Egorina EM, Chen A, Negro A, Perrin MH, Mjos OD, Latchman DS, Lee KF, Vale W: Urocortin-II and urocortin-III are cardioprotective against ischemia reperfusion injury: an essential endogenous cardioprotective role for corticotropin releasing factor receptor type 2 in the murine heart. Endocrinology 2004, 145:24-35. discussion 21-23

47. Davis ME, Pemberton CJ, Yandle TG, Fisher SF, Lainchbury JG, Frampton CM, Rademaker MT, Richards AM: Urocortin 2 infusion in healthy humans: hemodynamic, neurohormonal, and renal responses. J Am Coll Cardiol 2007, 49:461-471

48. Davis ME, Pemberton CJ, Yandle TG, Fisher SF, Lainchbury JG, Frampton CM, Rademaker MT, Richards M: Urocortin 2 infusion in human heart failure. Eur Heart J 2007, 28:2589-2597

49. Smani T, Calderon E, Rodriguez-Moyano M, DominguezRodriguez A, Diaz I, Ordonez A: Urocortin-2 induces vasorelaxation of coronary arteries isolated from patients with heart failure. Clin Exp Pharmacol Physiol 2011, 38:71-76

50. Neurath MF: Cytokines in inflammatory bowel disease. Nat Rev Immunol 2014, 14:329-342

51. van Dullemen HM, van Deventer SJ, Hommes DW, Bijl HA, Jansen J, Tytgat GN, Woody J: Treatment of Crohn's disease with anti-tumor necrosis factor chimeric monoclonal antibody (cA2). Gastroenterology 1995, 109:129-135

52. Suzuki Y, Saito H, Kasanuki J, Kishimoto T, Tamura Y, Yoshida S: Significant increase of interleukin 6 production in blood mononuclear leukocytes obtained from patients with active inflammatory bowel disease. Life Sci 1990, 47:2193-2197

53. Torricelli M, Voltolini C, Bloise E, Biliotti G, Giovannelli A, De Bonis M, Imperatore A, Petraglia F: Urocortin increases IL-4 and IL10 secretion and reverses LPS-induced TNF-alpha release from human trophoblast primary cells. Am J Reprod Immunol 2009, 62 : 224-231

54. Rassouli O, Liapakis G, Lazaridis I, Sakellaris G, Gkountelias K, Gravanis A, Margioris AN, Karalis KP, Venihaki M: A novel role of peripheral corticotropin-releasing hormone $(\mathrm{CRH})$ on dermal fibroblasts. PLoS One 2011, 6:e21654

55. Markovic D, Bari MF, Lu B, Vatish M, Grammatopoulos DK: Corticotropin-releasing hormone interacts with interleukin-1beta to regulate prostaglandin $\mathrm{H}$ synthase-2 expression in human myometrium during pregnancy and labor. J Clin Endocrinol Metab 2013, 98: 2864-2875

56. Huang M, Kempuraj D, Papadopoulou N, Kourelis T, Donelan J, Manola A, Theoharides TC: Urocortin induces interleukin-6 release from rat cardiomyocytes through p38 MAP kinase, ERK and NFkappaB activation. J Mol Endocrinol 2009, 42:397-405

57. Akira S: Roles of STAT3 defined by tissue-specific gene targeting. Oncogene 2000, 19:2607-2611

58. Pickert G, Neufert C, Leppkes M, Zheng Y, Wittkopf N, Warntjen M, Lehr HA, Hirth S, Weigmann B, Wirtz S, Ouyang W, Neurath MF, Becker C: STAT3 links IL-22 signaling in intestinal epithelial cells to mucosal wound healing. J Exp Med 2009, 206:1465-1472

59. Goldsmith JR, Uronis JM, Jobin C: Mu opioid signaling protects against acute murine intestinal injury in a manner involving Stat3 signaling. Am J Pathol 2011, 179:673-683

60. Lovato P, Brender C, Agnholt J, Kelsen J, Kaltoft K, Svejgaard A, Eriksen KW, Woetmann A, Odum N: Constitutive STAT3 activation in intestinal T cells from patients with Crohn's disease. J Biol Chem 2003, 278:16777-16781

61. Welte T, Zhang SS, Wang T, Zhang Z, Hesslein DG, Yin Z, Kano A, Iwamoto Y, Li E, Craft JE, Bothwell AL, Fikrig E, Koni PA, Flavell RA, Fu XY: STAT3 deletion during hematopoiesis causes Crohn's disease-like pathogenesis and lethality: a critical role of STAT3 in innate immunity. Proc Natl Acad Sci U S A 2003, 100: 1879-1884

62. Alonzi T, Newton IP, Bryce PJ, Di Carlo E, Lattanzio G, Tripodi M, Musiani P, Poli V: Induced somatic inactivation of STAT3 in mice triggers the development of a fulminant form of enterocolitis. Cytokine 2004, 26:45-56

63. Grivennikov S, Karin E, Terzic J, Mucida D, Yu GY, Vallabhapurapu S, Scheller J, Rose-John S, Cheroutre H, Eckmann L, Karin M: IL-6 and Stat3 are required for survival of intestinal epithelial cells and development of colitis-associated cancer. Cancer Cell 2009, 15:103-113 